\title{
The necessity of continuing to ban tobacco use in public places post-COVID-19
}

Fatimah El-Awa, ${ }^{1}$ Charles Patrick Fraser, ${ }^{1}$ Keyrellous Adib, ${ }^{1}$ Asmus Hammerich, ${ }^{1}$ Nisreen Abdel Latif, ${ }^{1}$ anti Fayokun, ${ }^{2}$ Vinayak Prasad, ${ }^{2}$ Dongbo Fu, Gemma Vestal, ${ }^{2}$ Kerstin Schotte, ${ }^{2}$ Heba Gouda ${ }^{2}$ and Simone St Claire ${ }^{2}$

${ }^{1}$ World Health Organization Regional Office for the Eastern Mediterranean, Cairo, Egypt. ${ }^{2}$ World Health Organization Headquarters, Geneva, Switzerland. (Correspondence to: Charles Patrick Fraser: cfraser@who.int).

Citation: El-Awa F; Fraser CP; Adib K; Hammerich A; Abdel Latif N; Ranti Fayokun R; et al. The necessity of continuing to ban tobacco use in public places post-COVID-19. East Mediterr Health J. 2020;26(6):630-632. https://doi.org/10.26719/emhj.20.071

Received: 06/05/20; accepted: 26/05/20

Copyright (C) World Health Organization (WHO) 2020. Open Access. Some rights reserved. This work is available under the CC BY-NC-SA 3.0 IGO license (https://creativecommons.org/licenses/by-nc-sa/3.o/igo).

\section{Introduction}

The coronavirus disease 2019 (COVID-19) emerged in late 2019 and has since been declared a pandemic by the World Health Organization (WHO). Millions of cases have been reported globally and in all 22 countries of the WHO's Eastern Mediterranean Region (EMR) (1).

In the EMR, 15 countries have temporarily banned waterpipe use in both indoor and outdoor public places in response to the COVID-19 pandemic ${ }^{1}$. This coincided with the release of the WHO Regional Office for the Eastern Mediterranean (WHO/EMRO) "Questions and Answers on Tobacco, Waterpipe and E-cigarette Use in the context of COVID-19" in March 2020 (2). The prohibition is the first of its kind after years of challenges in adopting and/or enacting such a ban (35). Countries in other WHO regions have also taken specific tobacco control policy measures related to the pandemic, including the banning of spitting in public places in India due to a potentially higher risk of transmission of the virus.

The policy response during the COVID-19 pandemic demonstrates that countries in the EMR have both the political will and technical means to adopt and implement strong tobacco control measures to protect public health. It is hoped that this can continue beyond the COVID-19 pandemic by sustaining these new measures at the national level.

\section{Tobacco use and COVID-19}

Evidence to date indicates that tobacco use, including waterpipe use, may further complicate health outcomes for COVID-19 patients $(2,6)$ and may be associated with an increased risk of more severe COVID-19 (7-10). Smoking is a known risk-factor for the prevalence and severity of many acute and chronic respiratory infections, including influenza, pneumonia and tuberculosis (11-13). Exposure to second-hand smoke is similarly risky (11).
In addition, the way tobacco, including waterpipe, is used may increase the risk of transmission of COVID-19 by compromising physical distancing in social and communal settings. Cigarette smoking involves the repetitive touching of the fingers and (potentially contaminated) cigarettes to the mouth. Smoking tobacco via waterpipe may increase transmission because waterpipes are often used in social settings that make physical distancing practically impossible. Moreover, equipment may be used by multiple users (despite changes in the mouthpiece) (14-17).

Stopping smoking has an almost immediate positive impact on respiratory and cardiovascular function and these benefits only increase with time (11). Within just 20 minutes of quitting, an ex-smoker's heart rate drops, and within 12 hours, the carbon monoxide level in the blood drops to normal. Within 2-12 weeks, the risk of heart attack begins to drop, and lung function begins to improve.

\section{Policy considerations in connection to COVID-19 and beyond}

The burden of tobacco use in the EMR has always been substantial (18). In some countries the prevalence of tobacco smoking is as high as 50\% among adult males, while in several countries youth tobacco use is above $30 \%(19,20)$. Strong and sustainable policies are needed to meet the global target of a $30 \%$ relative reduction in adult tobacco use by 2025 (21).

The COVID-19 pandemic has increased awareness about the dangers of tobacco use. The momentum now exists for strengthening tobacco control polices, including in the 19 EMR Member States that are parties to the WHO Framework Convention on Tobacco Control (WHO FCTC). Immediate action to strengthen tobacco control policies post-COVID-19, including a permanent ban on tobacco use in public places, accompanied by awareness campaigns, will contribute to reducing the rates of tobacco smoking and accordingly may

In response to the COVID-19 pandemic, 15 countries in the EMR have introduced a temporary ban on waterpipe use in all indoor and outdoor public places. This is in addition to the two countries in the EMR that had already introduced a permanent ban on waterpipe use in all public places prior to the COVID-19 pandemic. 
reduce susceptibility and vulnerability to different communicable diseases.

Banning tobacco use in public places during COVID-19 shows that countries have both the political will and capacity to implement such policies. Countries in the Region can build on their success by considering sustaining the ban on tobacco use in all public places. This ban should include all forms of tobacco and e-cigarette use in indoor public places.

It is also important to note that during the COVID-19 response, people are spending longer periods at home, increasing the risk of second-hand and third-hand smoke exposure, which is especially dangerous for children $(11,22)$. Consequently, running awareness campaigns about the dangers of such exposure, including in the home, is important. In addition, policy-makers could consider limiting access to tobacco products from the home (e.g. limiting access via home delivery).

Relatedly, strengthening cessation services will be essential in order to meet a likely increased demand for quitting tobacco. While physical distancing measures continue, innovative approaches to providing cessation services are needed. Toll-free tobacco quit lines, mobile services and digital health solutions to ensure broad access may be even more important at this time (23).

\section{Conclusion}

It is important to further explore the relation between tobacco use and COVID-19. Countries are encouraged to collect relevant and reliable national level data to examine this association. However, even the existing evidence provides good reason to pursue the full implementation of high-impact tobacco control measures during and after the COVID-19 pandemic.

In light of the measures taken so far to control tobacco use in public places in the context of COVID-19, countries have a rare opportunity to imbed a more sustainable approach to tobacco control at the national level. In addition to tobacco-free public places, such an approach will need to consider all other key tobacco control measures, including effective graphic health warnings, increasing tobacco taxes and banning all forms of tobacco advertising, promotion and sponsorship. Furthemore, measures to control illicit trade in tobacco products and the use of e-cigarettes, which are also harmful to the heart and lungs, are needed. In addition, it is important to monitor tobacco industry tactics and strategies during the COVID-19 pandemic and beyond to prevent future interference and influence in tobacco control policy-making (24).

A comprehensive, multi-sectoral and all-ofgovernment approach to tobacco control, which takes into account all articles of the WHO FCTC, is needed to end the tobacco epidemic and save lives (25).

\section{References}

1. World Health Organization. Rolling updates on coronavirus disease (COVID-19). Geneva: World Health Organization; 2020. (https://www.who.int/emergencies/diseases/novel-coronavirus-2019/events-as-they-happen, accessed 13 May 2020).

2. World Health Organization Regional Office for the Eastern Mediterranean (WHO/EMRO). Tobacco and waterpipe use increases the risk of suffering from COVID-19. Tobacco Free Initiative. Cairo: WHO/EMRO; 2020 (http://www.emro.who.int/tfi/know-thetruth/tobacco-and-waterpipe-users-are-at-increased-risk-of-covid-19-infection.html, accessed 12 May 2020).

3. World Health Organization. Exposure to second-hand smoke in selected public places in the WHO Eastern Mediterranean Region. Geneva: World Health Organization; 2012 (https://apps.who.int/iris/handle/10665/116793, accessed 12 May 2020).

4. World Health Organization. WHO Report on the Global Tobacco Epidemic. Geneva: World Health Organization; 2019 (https:// www.who.int/tobacco/global_report/en/, accessed 12 May 2020).

5. El-Awa F; Bettcher D; Al-Lawati JA; Alebshehy R; Gouda H; Fraser CP. The status of tobacco control in the Eastern Mediterranean Region: progress in the implementation of the MPOWER measures. East Mediterr Health J. 2020;26(1):102-109. https://doi. org/10.26719/2020.26.1.102

6. WHO FCTC Knowledge Hub for Waterpipe Tobacco Smoking. Increased risk of COVID-19 infection amongst smokers and amongst waterpipe users. [Online] 2020. (https://untobaccocontrol.org/kh/waterpipes/covid-19/, accessed 13 May 2020).

7. Vardavas C, Nikitara K. COVID-19 and smoking: A systematic review of the evidence. Tob Induc Dis. 2020;18:20 DOI:10.18332/ tid/119324

8. Liu W, Tao Z, Lei W, Ming-Li Y, Kui L, Ling Z, et al. Analysis of factors associated with disease outcomes in hospitalized patients with 2019 novel coronavirus disease. Chinese Med J. 2020;133(9):1032-1038.

9. Alqahtani J, Oyelade T, Aldahir A, Alghamdi S, Almehmadi M, Alqahtani A, et al. Prevalence, Severity and Mortality associated with COPD and Smoking in patients with COVID-19: A Rapid Systematic Review and Meta-Analysis. Plos One. 2020; 15(5).

10. Patanavanich R, Glantz S. Smoking is associated with COVID-19 progression: A meta-analysis. Nicotine and Tobacco Research. 2020: ntaa082. DOI:10.1093/ntr/ntaa082.

11. U.S. Department of Health and Human Services, Centers for Disease Control and Prevention, National Center for Chronic Disease Prevention and Health Promotion, Office on Smoking and Health. The health consequences of smoking: 50 years of progress - A report by the Surgeon General. 2014 (https://www.cdc.gov/tobacco/data_statistics/sgr/5oth-anniversary/index.htm, accessed 12 May 2020).

12. Han L, Ran J, Mak Y, Suen L, Lee P, Peiris J, et al. Smoking and Influenza-associated Morbidity and Mortality: A Systematic Review and Meta-analysis. Epidemiology. 2019;30(3):405-417. 
13. Feldman C, Anderson R. Cigarette smoking and mechanisms of susceptibility to infections of the respiratory tract and other organ systems. J Infect. 2013;67(3):169-184

14. Maziak W, Taleb Z, Bahelah R, Islam F, Jaber R, Auf R, et al. The global epidemiology of waterpipe smoking. Tob Control. 2015;24(Suppl 1):3-12.

15. WHO Study Group on Tobacco Product Regulation. Waterpipe tobacco smoking: health effects, research needs and recommended actions for regulators (2nd ed.). Geneva: World Health Organization; 2015.

16. Koul P, Hajni M, Sheikh M, Khan U, Shah A, Khan Y, et al. Hookah smoking and lung cancer in the Kashmir valley of the Indian subcontinent. Asian Pac J Cancer P. 2011;12(2):519-24.

17. Daniels K, Roman N. A descriptive study of the perceptions and behaviors of waterpipe use by university students in the Western Cape, South Africa. Tob Induc Dis. 2013;11(1).

18. World Health Organization. Global Report on Trends in the Prevalence of Tobacco Use (3rd Edition). Geneva: World Health Organization; 2019. (https://www.who.int/publications-detail/who-global-report-on-trends-in-prevalence-of-tobacco-use-20oo2025-third-edition, accessed 12 May 2020).

19. World Health Organization Regional Office for the Eastern Mediterranean (WHO/EMRO). STEPwise Survey of NCD Risk-Factors Factsheets 2012-2019. Cairo: WHO/EMRO; 2020 (http://www.emro.who.int/tfi/statistics/index.html., accessed 12 May 2020).

20. World Health Organization Regional Office for the Eastern Mediterranean (WHO/EMRO). Global Youth Tobacco Survey Factsheets 2007-2018. Cairo: WHO/EMRO; 2020 (http://www.emro.who.int/tfi/statistics/index.html., accessed 12 May 2020).

21. World Health Organisation. WHO Global Action Plan for the Prevention and Control of Noncommunicable Diseases $2013-2020$. Geneva: World Health Organization; 2013. (https://apps.who.int/iris/bitstream/handle/10665/94384/9789241506236_eng.pdf?sequence $=1$, accessed 17 May 2020).

22. Jacob P, Benowitz N, Destaillats H, Gundel L, Hang B, Martins-Green M, et al. Thirdhand Smoke: New Evidence, Challenges, and Future Directions. Chem Res Toxicol. 2017;30(1):270-294.

23. Berlin I, Thomas D, Le Faou A, Cornuz J. COVID-19 and Smoking. Nicotine and Tobacco Research. 2020: 1-3; ntaa059. DOI: 10.1093/ntr/ntaa059.

24. Global Center for Good Governance in Tobacco Control. COVID-19 and Tobacco Industry Interference. [Online] 2020. (https:// ggtc.world/2020/03/24/covid-19-and-tobacco-industry-interference-2020/, accessed 12 May 2020).

25. Al-Mandhari A; Hammerich A; El-Awa F; Bettcher D; Mandil A. Full implementation of the WHO Framework Convention on Tobacco Control in the Eastern Mediterranean Region is the responsibility of all. East Mediterr Health J. 2020;26(1):4-5. https:// doi.org/10.26719/2020.26.1.4 